\title{
EVALUATION OF PULMONARY HYPERTENSION IN CHRONIC OBSTRUCTIVE PULMONARY DISEASE
}

\section{G. Peter Praveen Herald ${ }^{1}$, H Krishna Murthy *2.}

${ }^{1}$ Assistant Professor, Department of Pulmonary Medicine, Viswabharthi Medical college, Penchikalapadu, Kurnool, Andhra Pradesh, India.

${ }^{* 2}$ Head of the Department of Pulmonary Medicine, Viswabharthi Medical college, Penchikalapadu, Kurnool, Andhra Pradesh, India.

\section{ABSTRACT}

Introduction: The early detection and treatment of pulmonary hypertension in chronic obstructive pulmonary disease (COPD) becomes important to prevent right heart failure. We aimed to pulmonary hypertension in COPD patients by non-invasive methods.

Materials and Methods: After Ethical committee clearance, the purpose of the study was explained to the patient and obtained informed consent from 105 Clinically diagnosed as COPD were included and ECG, Chest X-Ray, 2D Echocardiography pulmonary hypertension is evaluated.

Results: Of 105 COPD patients, 96 had PH. Prevalence of pulmonary hypertension in COPD patients were 54 (51.43\%): 9 (25.71\%) of mild COPD patients, 16 (45.71\%) of moderate COPD and 29 (82.85\%) of severe COPD.

Conclusion: the chest radiography electrocardiography and $2 \mathrm{D}$-Echocardiography are the best clinical assessment and non-invasive investigations for the screening for pulmonary hypertension and subsequent development of cor pulmonale.

KEY WORDS: Chronic Obstructive Pulmonary Disease, Cor Pulmonale, Magnetic Resonance Imaging, Pulmonary Hypertension.

Address for correspondence: Dr. H Krishna Murthy, Head of the Department of Pulmonary Medicine, Viswabharthi Medical college, Penchikalapadu, Kurnool, Andhra Pradesh. 9440557565. E-Mail:drkrishhmurthy56@gmail.com, peterpraveenherald@gmail.com

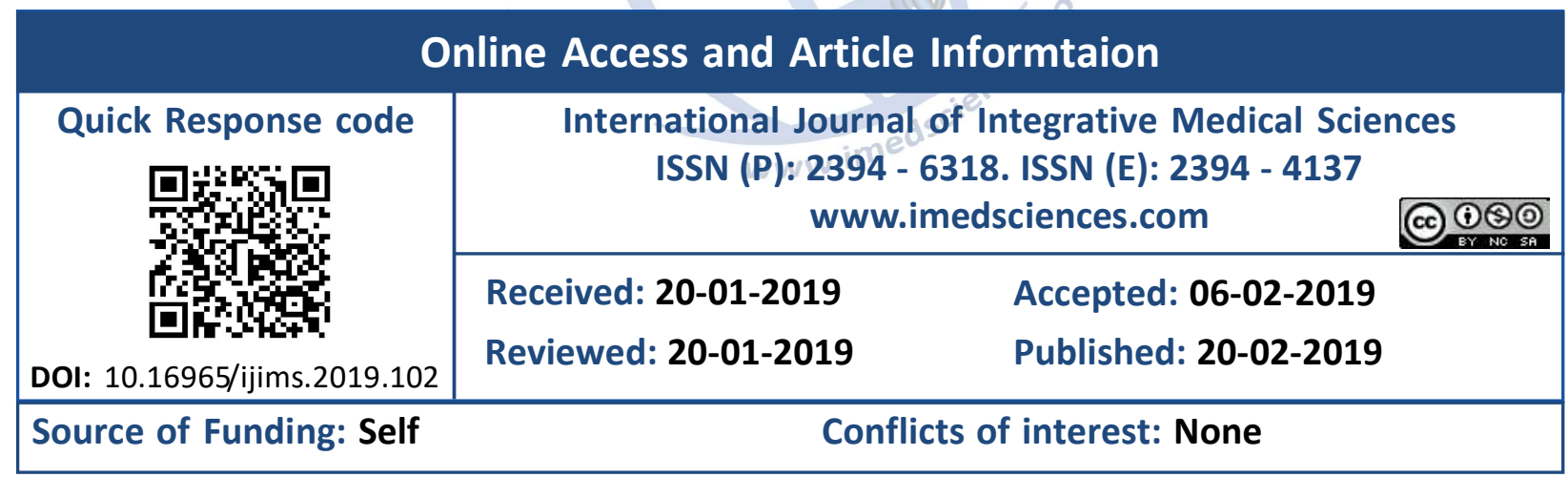

\section{INTRODUCTION}

Chronic Obstructive Pulmonary Disease (COPD) is a major cause of health care burden worldwide and the only leading cause of death that is increasing in prevalence. It is the fourth leading cause of death, and by 2020 , is expected to rise to the $3^{\text {rd }}$ position as a cause of death [1].

Pulmonary hypertension is a serious complication of COPD and is associated with poor prognosis. In general, Pulmonary hypertension is said to be present when Mean pulmonary artery pressure (Ppa) is more than $25 \mathrm{~mm} \mathrm{Hg}$, in COPD when pressure is above $20 \mathrm{~mm} \mathrm{Hg}$. Pulmonary hypertension associated with COPD is usually mild to moderate, and in $\angle 5 \%$ patients it is severe. COPD is a preventable and treatable disease with some significant extra pulmonary effects that may contribute to the severity in individual patients. Its pulmonary component is characterized by airflow limitation that is not fully reversible. The airflow limitation is progressive and associated with an abnormal inflammatory response of the lung to noxious stimuli [1]. Pulmonary hypertensions in COPD is attributed to hypoxia induced 
pulmonary vasoconstriction, it can be easily corrected by supplemental oxygen [2]. In view of high prevalence of pulmonary hypertension complicating severe COPD, and poor predictive power of lung indices, all COPD patients should be screened for pulmonary hypertension. It helps in assessment of prognosis in COPD patients [3].

Pressure is known to increase to a great extent during REM sleep, exercise, acute exacerbations which, eventually leads to right heart failure. Thus, early detection and treatment of pulmonary hypertension becomes important to prevent right heart failure [4]. This study is an attempt to study prevalence of COPD patients, development of pulmonary hypertension in them.

\section{MATERIALS AND METHODS}

After Ethical committee clearance, the purpose of the study was explained to the patient and obtained informed consent from 105 Clinically diagnosed as COPD (mainly emphysema and chronic bronchitis) with subsequent confirmation by spirometry i.e., FEV1/FVC $<0.7$ were included in the study and Bronchial asthma, Pulmonary Tuberculosis (present or past), Interstitial lung diseases, Valvular heart diseases, Acute Left Ventricular Failure and Pulmonary edema secondary to other causes (hypertension, ischemic heart disease, cardiomyopathies), Primary pulmonary hypertension, Bronchiectasis were not included in the study from the outpatient department or undergoing inpatient treatment at Viswabharthi Medical college, Penchikalapadu, Kurnool, Andhra Pradesh during the period of December 2017 to June 2018. Data was collected using a pretested proforma meeting the objectives of the study. Detailed history, physical examination and necessary investigations was undertaken. Pulmonary function testing was done using HELIOS 401 spirometer. COPD was diagnosed and classified according to BTS guidelines (BTS post bronchodilator FEV1/FVC $<70 \%$ and FEV1 $<80 \%$ predicted), mild (FEV1 60- 80\% of predicted), moderate (FEV1 40$59 \%$ predicted) and severe (FEV $1<40 \%$ predicted) respectively. Using non-invasive methods like ECG, Chest X-Ray, 2-DEchocardiography pulmonary hypertension was evaluated in diagnosed COPD patients.
Echocardiography: All the participants were subjected to trasthorasic echocardiography. The standardized protocol included 2- dimensional scanning in the parasternal long and short axis views, apical and subcostal views. In addition, left ventricular dimensions were measured using 2-dimension guided M-mode. Tricuspid regurgitation peak velocity (TRV) was measured using Continuous Wave Doppler. Tissue Doppler imaging was done in the apical 4- chamber view. Echocardiograms were made using a commercially available ultrasonography system (Vivid I, GE Healthcare, Little Chalfont, UK), with a 2.5 $\mathrm{MHz}$ transducer.

Pulmonary artery systolic pressure: Pulmonary artery systolic pressure was calculated as the sum of the estimated right atrial pressure (RAP) according to the guidelines of the American Society of Echocardiography and the pressure gradient over the tricuspid valve as: ePASP $=4 *$ TRV2 + RAP. The pressure gradient was computed from the highest Doppler tricuspid regurgitation velocity gathered from several windows using the simplified Bernoulli equation ( $4 * T R V 2$ ). If the inferior vena cava diameter was d" $21 \mathrm{~mm}$ and its forced inspiratory collapse ("sniff test") was $>50 \%$, RAP was estimated to be $3 \mathrm{mmHg}$; if the diameter was $>21 \mathrm{~mm}$ and the collapse $<50 \%$, RAP was estimated as $15 \mathrm{mmHg}$; in intermediate cases, a value of $8 \mathrm{mmHg}$ was assigned. Participants were deemed to have ePH if they had ePASP $>40 \mathrm{mmHg}$. If data on RAP was missing, a tricuspid pressure gradient $>36 \mathrm{mmHg}$ (TRV >3.0 m/s) criterion was used instead.

\section{RESULTS}

Table 1: Showing the Age and sex distribution.

\begin{tabular}{|l|c|c|c|c|c|c|}
\hline \multirow{2}{*}{\multicolumn{1}{|c|}{ SEX }} & \multicolumn{2}{|c|}{ Male } & \multicolumn{2}{c|}{ Female } & \multicolumn{2}{c|}{ Total } \\
\cline { 2 - 7 } & No & $\%$ & No & $\%$ & No & $\%$ \\
\hline Mild COPD & 20 & 57.1 & 15 & 42.86 & 35 & 100 \\
\hline Moderate COPD & 18 & 51.4 & 17 & 48.57 & 35 & 100 \\
\hline Severe COPD & 23 & 65.7 & 12 & 34.29 & 35 & 100 \\
\hline Total COPD & 61 & 58.09 & 44 & 41.91 & 105 & 100 \\
\hline
\end{tabular}


Table 2: Showing the Chest radiography findings in COPD Groups. The following parameters were studied in the chest radiography. 1. Presence or absence of emphysema 2. Cardiomegaly 3. Prominent pulmonary conus (PPC).

\begin{tabular}{|l|c|c|c|c|c|c|}
\hline \multirow{2}{*}{ SEX } & \multicolumn{2}{|c|}{ Emphysema } & \multicolumn{2}{c|}{ Cardiomegaly } & \multicolumn{2}{c|}{ Prominent pulmonary } \\
\cline { 2 - 8 } & No & $\%$ & No & $\%$ & No & $\%$ \\
\hline Mild COPD & 9 & 25.71 & 1 & 2.86 & 2 & 5.71 \\
\hline Moderate COPD & 16 & 45.71 & 4 & 11.43 & 5 & 14.29 \\
\hline Severe COPD & 17 & 48.57 & 18 & 51.43 & 13 & 37.14 \\
\hline Total COPD & 42 & 40 & 23 & 21.9 & 20 & 19.04 \\
\hline
\end{tabular}

Table 3: Showing the Electrocardiographic findings.

\begin{tabular}{|l|c|c|c|c|c|c|c|c|}
\hline \multirow{2}{*}{ SEX } & \multicolumn{2}{|c|}{ 'P' Pulmonale } & \multicolumn{2}{c|}{ R/S in V6 $<1$} & \multicolumn{2}{|c|}{ RAD } & \multicolumn{2}{c|}{ RBBB } \\
\cline { 2 - 10 } & No & $\%$ & No & $\%$ & No & $\%$ & No & $\%$ \\
\hline Mild COPD & 9 & 25.71 & 3 & 8.57 & 2 & 5.71 & 2 & 5.71 \\
\hline Moderate COPD & 14 & 40 & 9 & 25.71 & 7 & 20 & 3 & 8.57 \\
\hline Severe COPD & 16 & 45.71 & 14 & 40 & 12 & 34.29 & 5 & 14.29 \\
\hline Total COPD & 39 & 37.14 & 26 & 24.76 & 21 & 19.04 & 10 & 9.52 \\
\hline
\end{tabular}

\section{DISCUSSION}

The early detection and treatment of pulmonary hypertension in chronic obstructive pulmonary disease (COPD) becomes important to prevent right heart failure. We aimed to pulmonary hypertension in COPD patients by non-invasive methods. After Ethical committee clearance, the purpose of the study was explained to the patient and obtained informed consent from 105 Clinically diagnosed as COPD were included and ECG, Chest X-Ray, 2-D Echocardiography pulmonary hypertension is evaluated.

The FEV1, FVC and FEV1\% were significantly altered, inversely and significantly related to severity of COPD $(P<0.05)$. Cardiomegaly was significantly more common in patients with severe COPD group. The most common abnormality observed was $P$ pulmonale. This was seen more commonly in patients with severe obstruction although not statistically significant. The $\mathrm{R} / \mathrm{S}$ ratio in $\mathrm{V} 6<1$ correlated significantly well with the severity of COPD. Success rate of Echocardiographic examination: In this study 105 patients were screened to get the desired 96 subjects in the study, success rate of $91.43 \%$ this is almost comparable with other authors success rate: Shruthi Reddy et al (success rate of approx 96.16\%). [5]. The success rate of 2DEchocardiography in the present study is around $91.43 \%$, which is comparable to other studies.
The reasons for the failure rate observed are thick barrier of air in emphysematous chest preventing adequate penetration by ultrasonic waves and the altered anatomy and position of the heart in the chest making correct direction and angulation of the echo probe extremely uncertain.

Prevalence of pulmonary hypertension in COPD patients were 54 (51.43\%): 9 (25.71\%) of mild COPD patients, 16 (45.71\%) of moderate COPD and $29(82.85 \%)$ of severe COPD. some of the patients with mild COPD tend to have features of pulmonary hypertension as evidenced by ECG and Echocardiographic Parameters in the present study. The prevalence of this study is similar with prevalence of previous studies. Although the true prevalence of $P H$ in COPD is unknown, an elevation of pulmonary arterial pressure is reported to occur in 20 percent -90 percent of patients when measured by right heart catheterization with some evidence that pulmonary hemodynamic worsening airflow obstruction [6-11].

Two studies have shown an abnormal increase in mean pulmonary arterial pressure in COPD of 0.4-0.6 $\mathrm{mm} \mathrm{Hg}$ per year. These studies illustrate that PH in COPD progresses slowly and occurs in mild as well as severe forms of disease [1213]. In a study by Shruthi Reddy et al [5], the frequencies of $\mathrm{PH}$ in mild, moderate, severe, and very severe COPD were $25 \%, 43 \%$, and $68 \%$ in mild, moderate, and severe COPD respectively. Approximately 25 percent patients with COPD eventually develop cor pulmonale [14]. Cor pulmonale was found in 40 percent patients with COPD in one autopsy study $[15,16]$. It is estimated that every year between 10 percent and 30 percent of all hospital admissions for heart failure in united states are due to cor pulmonale [17] and approximately 85 percent patients with cor pulmonale have COPD [18].

\section{CONCLUSION}

The present study accentuates the importance chest radiography electrocardiography and $2 \mathrm{D}$ Echocardiography are the best clinical assessment and non-invasive investigations for the screening for pulmonary hypertension and subsequent development of cor pulmonale and its prevalence. 


\section{REFERENCES}

[1]. John R Reilly, Jr, Edwin K Silverman, Steven D Shapiro, Chronic Obstructive Pulmonary Disease, Chapter 254, Harrison's Principles of Internal Medicine, Fauci, Braunwald, Kasper, Hauser, Longo, Jameson, Loscalzo, 17th edition, Page 1635.

[2]. Guidelines for diagnosis and treatment of Pulmonary Hypertension by European society of Cardiology and European respiratory society. European Heart Journal .2009; 30:2493-537.

[3]. Michel Migueres. Pulsed Doppler echocardiography in diagnosis of Pulmonary Hypertension in COPD, CHEST. 1990; 98:280-5.

[4]. Global Strategy for the Diagnosis, Management \& Prevention of Chronic Obstructive Pulmonary Disease. American Journal of Respiratory and Critical Care Medicine.2007;176:532-55.

[5]. Shruthi Reddy, Rajender, Nithin Reddy. Prevalence of Pulmonary Hypertension in COPD Patients: A Retrospective Observational Study. Int J Intg Med Sci 2016;3(5):285-9.

[6]. Weitzenblum E, Hirth C, Ducolone A, Mirhom R, Rasaholinjanahary J, Ehrhart M. Prognostic value of pulmonary artery pressure In chronic COPD: Thorax. 1981;36:752-8.

[7]. Weitzenblum E, Sautegeau A, Ehrhart M, Mammosser $M$, Hirth C, Roegel E. long term course of pulmonary artery pressure In chronic COPD. Am Rev Respir Dis. 1984;130:993-8.

[8]. Burrows B, Kettel L, Niden AH, Rabinowitz M, Diener CF. Patterns of cardiovascular dysfunction in COPD. N Engl J Med. 1972;286:912-8.

[9]. Fishman AP. State of the art: Chronic cor pulmonale. Am Rev Respir Dis. 1976;114:775-94.

[10]. Pietra G. Pathology of the pulmonary vasculature and heart. In; Cherniack N, editor. COPD. Philadelphia: WB Saunders; 1996;21-6.
[11]. Thabut G, Dauriat G, Stern JB, Logeart D, Lévy A, Marrash-Chahla $R$, et al: Pulmonary haemodynamics in advanced COPD candidates for lung volume reduction surgery or lung transplantation. Chest. 2005;127:1531-6.

[12]. Weitzenblum E, Hirth C, Ducolone A, Mirhom R, Rasaholinjanahary J, Ehrhart M. Prognostic value of pulmonary artery pressure In chronic COPD: Thorax. 1981;36:752-8.

[13]. Weitzenblum E, Sautegeau A, Ehrhart M, Mammosser $M$, Hirth C, Roegel E. long term course of pulmonary artery pressure In chronic COPD. Am Rev Respir Dis .1984;130:993-8.

[14]. Thabut G, Dauriat G, Stern JB, Logeart D, Lévy A, Marrash-Chahla $R$, et al: Pulmonary haemodynamics in advanced COPD candidates for lung volume reduction surgery or lung transplantation. Chest.2005;127:1531-6.

[15]. Weitzenblum E, Sautegeau A, Ehrhart M, Mammosser $M$, Pelletier $A$. Long-term oxygen therapy can reverse the progression of pulmonary hypertension in patients with chronic obstructive pulmonary disease. Am Rev Respir Dis.1985;131:493-8.

[16]. Kessler R, Faller M, Weitzenblum E, Chaouat A, Aykut A, Ducolone'A, et al. "Natural history" of pulmonary hypertension in a series of 131 patients with chronic obstructive pulmonary disease. Am J Respir Crit Care Med. 2001;164:219-24.

[17]. Oswald-Mammosser M, Weitzenblum E, Quoix E, Moser G, Chaouat A, Charpentier C, et al. Prognostic factors in COPD patients receiving long-term oxygen therapy. Chest.1995;107:1193-8.

[18]. Fishman AP. State of the art: Chronic cor pulmonale. Am Rev Respir Dis.1976;114:775-94.

$$
\begin{aligned}
& \text { How to cite this article: G. Peter Praveen Herald, H Krishna Murthy. } \\
& \text { EVALUATION OF PULMONARY HYPERTENSION IN CHRONIC } \\
& \text { OBSTRUCTIVE PULMONARY DISEASE. Int J Intg Med Sci 2019;6(1):765- } \\
& \text { 768. DOI: } 10.16965 / \text { ijims. } 2019.102
\end{aligned}
$$

